\title{
ESTUDIO DE LA MOVILIDAD CICLISTA EN UN SECTOR DE LOS CANTONES CARTAGO Y EL GUARCO, DE LA PROVINCIA CARTAGO, COSTA RICA
}

\author{
BICYCLE MOBILITY STUDY IN A SECTOR OF \\ THE CARTAGO AND EL GUARCO TOWNS OF THE \\ PROVINCE OF CARTAGO, COSTA RICA
}

\author{
Mauricio Torres-Paniagua ${ }^{1}$ \\ Henry Hernández-Vega ${ }^{2}$ \\ Universidad de Costa Rica
}

\section{RESUMEN}

El presente artículo presenta un resumen de un estudio de la movilidad en bicicleta en sectores de los distritos San Francisco, Guadalupe y Quebradilla del cantón de Cartago, y de los distritos Tobosi y Tejar del cantón El Guarco, en Costa Rica. El estudio de movilidad incluyó la evaluación de mapas con curvas de nivel en el sector con el fin de determinar las zonas que presentan una topografía favorable para el tránsito en bicicleta, esto se complementó con una caracterización de la zona, con ayuda de mapas de uso de suelo y visitas al sitio, que permitieron identificar los principales atractores y generadores de viajes. Se efectuaron conteos de bicicletas y encuestas para estudiar la movilidad y caracterizar a los ciclistas. Se generó una red de movilidad ciclista. Los usuarios de bicicleta en la zona, son generalmente adultos jóvenes quienes viajan por motivo de trabajo y que

1 Egresado Escuela de Ingeniería Civil. Universidad de Costa Rica. Correo electrónico: mtorres23@ gmail.com

2 Investigador Programa Infraestructura del Transporte. Laboratorio Nacional de Materiales y Modelos Estructurales. Escuela de Ingeniería Civil. Universidad de Costa Rica. Correo Electrónico: henry. hernandezvega@ucr.ac.cr

Fecha de recepción: 01 de agosto de 2016

Fecha de aceptación: 07 de octubre de 2016 
Mauricio Torres-Paniagua, Henry Hernández-Vega. Bicycle mobility study in a sector of the

Cartago and el Guarco towns of the province of Cartago, Costa Rica

pertenecen a un estrato socioeconómico específico. La zona posee características espaciales que propician el ciclismo y que pueden ser potenciadas con mejoras en la infraestructura.

Palabras clave: transporte; bicicleta; movilidad.

\begin{abstract}
This article presents a summary of a bicycle mobility study in a region of the province of Cartago in Costa Rica. This mobility study includes the use of topographic map contour lines to establish the most favorable locations for cyclists, which was complemented with land use maps and site visits in order to identify the main sources of origin and destination for cyclists' trips. Bicycle counts were made at several points, also origin-destination surveys were conducted to study the mobility, and a detailed survey to characterize the cyclists in the region was performed. From the information that was collected, a cycling mobility network was generated. Most of the cyclists in this area are young adults of a similar socioeconomic status who travel for work purposes. It is evident that the area has spatial characteristics that can facilitate cycling by road infrastructure enhancement.
\end{abstract}

Keywords: transport, bicycle, mobility.

\title{
Introducción
}

Durante las últimas décadas, ha existido en muchos países una preocupación sobre el impacto ambiental generado por el uso del automóvil para el transporte de pasajeros (Canadian Institute of Transportation Engineers, 2004). Uno de los grandes problemas generalizados en Costa Rica, pero principalmente en las ciudades, es la ineficiencia del sistema de transporte, el cual trae repercusiones en ámbitos de salud, medio ambiente, movilidad de las personas y economía. Por ejemplo, Otoya (2009) estimó que los accidentes de tránsito (a partir de datos del 2005) y la congestión (a partir de datos del 2006) en el Gran Área Metropolitana (GAM) generan deseconomías del orden del 1,71 \% del Producto Interno Bruto (PIB).

A partir de esta preocupación ha surgido el concepto de transporte sostenible que promueve un balance entre los beneficios económicos y sociales del transporte con la salud humana y del ambiente (Canadian Institute of Transportation Engineers, 2004). Para lograr un desarrollo urbano sostenible de una ciudad es necesaria la creación de políticas públicas que fomenten el transporte público, el caminar o la bicicleta; brindando beneficios al ambiente y a la calidad de vida de la población, entre muchos otros. Por ejemplo, Laverty, Mindell, Webb, \& Millett (2013) determinaron que estos tres modos de transporte están asociados con una menor probabilidad de tener problemas de sobrepeso, también indican que caminar o usar 
la bicicleta para transportarse está asociada con una menor probabilidad de padecer diabetes.

Con el uso de estos modos de transporte se busca reducir la demanda de vehículos motorizados en las ciudades; para así mejorar la capacidad de planificación en la que se incluyan las necesidades de toda la población en el sistema de transporte, y no solo al poseedor de vehículo privado.

La priorización del peatón y la bicicleta permiten el desarrollo de una movilidad urbana con mayor equidad y sostenibilidad (Ministerio de Transportes de Colombia, 2016). Pucher, Dill \& Handy (2010) indican en su estudio que la política pública juega un papel fundamental en la promoción de la bicicleta. Además, un plan de movilidad ciclista es exitoso cuando se logran aumentar la cantidad de viajes en bicicleta (ITDP, 2011). Por otro lado, es preocupante el bajo uso de la bicicleta en el GAM, que corresponde solamente al dos por ciento de los viajes de acuerdo con L.C.R. Logística (2007).

A pesar de la importancia de incorporar la bicicleta en el desarrollo de políticas de movilidad, la cantidad de información relacionada con estudios de movilidad en bicicleta en el país era muy limitada al momento de realizar el estudio. La documentación disponible incluía a los estudios de Dobles (1981) y Fonseca (2010) que analizaron la movilidad en bicicleta en los alrededores de la Ciudad Universitaria Rodrigo Facio de la Universidad de Costa Rica y el estudio de Machado (2010) que investigó la demanda potencial de viajes en bicicleta para el GAM.

De acuerdo con ITDP (2011) y Acuña-Leiva, Hernández-Vega, Jiménez-Romero, Zamora-Rojas y Loría-Salazar (2016) es necesario generar un diagnóstico de la movilidad en bicicleta que permitan determinar las necesidades de los ciclistas para así generar un diseño apropiado de una red de movilidad en bicicleta.

La zona de estudio incluye los distritos San Francisco, Guadalupe y Quebradilla, del cantón Cartago, y los distritos Tobosi y Tejar, del cantón El Guarco. Al iniciar el proyecto se deseaba saber si era posible caracterizar la movilidad en bicicleta en la zona analizada. En la región estudiada existen muchos centros industriales y agroindustriales, los cuales son atractores de viajes, como por ejemplo, el Parque Industrial de Cartago, Central Veterinaria, Kimberly Clark, entre otras. En este sector se observó una cantidad considerable de ciclistas, sin tener ningún tipo de facilidad 
en infraestructura para sus viajes. Esto constituye la razón principal por la que se efectuó este estudio en esta zona del Valle de El Guarco. Por ejemplo, en la figura 1 se muestra el parqueo de bicicletas en la Jardinería Linda Vista en Barrancas de Tobosi, que evidencia la presencia de muchos ciclistas en este centro de trabajo.

El sector industrial de Cartago, ubicado en el distrito Guadalupe, unido a todos los centros de población cercanos es una región que, por las características de uso de suelo, la topografía plana y además la disponibilidad de espacio en los márgenes de las calles, debe ser especialmente analizada para la construcción de ciclovías o facilidades para ciclistas. Esto alentaría el uso de la bicicleta, además de beneficiar a los ciclistas que ya están presentes.

Figura 1. Parqueo para bicicletas en Jardinería Linda Vista. Barrancas, El Guarco

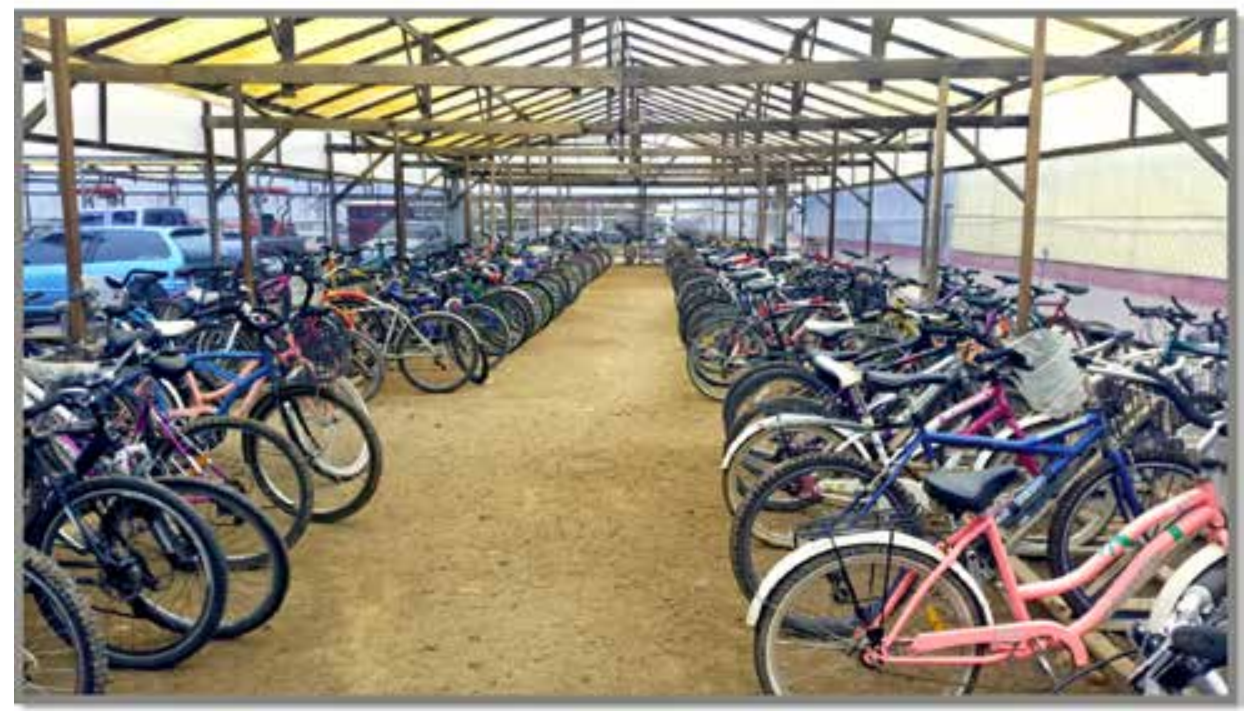

Fuente: Fotografía propia (Octubre, 2014)

Previo al desarrollo de este trabajo, el Ministerio de Obras Públicas y Transportes (MOPT) realizó un estudio en el cual se cuentan la cantidad de ciclistas y vehículos a la salida del Parque Industrial de Cartago; indica que en las tres horas pico, es decir en las horas de mayor volumen, 
transitan 653 ciclistas (MOPT, 2008). La Municipalidad de Cartago ha efectuado estudios de monitoreo del uso de la ciclovía de Cartago; sin embargo, en la zona de estudio no se han efectuado investigaciones relacionadas con los patrones de movilidad en bicicleta.

Esta investigación pretende caracterizar la movilidad en bicicleta en la zona con el fin de proponer una red de movilidad que podría ser utilizada por los ciclistas si se les brinda la adecuada infraestructura, para que tengan mejores condiciones de viaje, y así se aumenten la cantidad de viajes en bicicleta.

Además, se consultaron diferentes planes y estrategias de movilidad de diferentes lugares: Cantabria, España (Gobierno de Cantabria, 2012), Madrid, España (Ayuntamiento de Madrid, 2008), Vitoria-Gasteiz, España (Ayuntamiento de Vitoria-Gasteiz, s.f), Los Ángeles, Estados Unidos (Los Angeles Department of City Planning, 2011), Australia (Australian Bicycle Council, 2010), Ciudad de México (Secretaría del Medio Ambiente del Distrito Federal, 2012), Santiago, Chile (Gobierno Regional Metropolitano de Santiago, s.f. y 2012), Calgary, Canadá (City of Calgary, 1997) y Holanda (CROW, 2006).

\section{Metodología}

A continuación se explica el método seguido para el desarrollo del estudio.

\section{Diseño}

El diseño del estudio está basado en tres componentes principales: 1)caracterización geográfica de la zona incluyendo la identificación de potenciales zonas de origen y destino de viajes en bicicleta considerando la topografía, 2) conteos de bicicletas con equipo automático, conteos manuales en intersecciones y 3 ) encuestas origen-destino.

Inicialmente se tomaron mapas con curvas de nivel para identificar las zonas con pocas pendientes (zonas relativamente planas) que conforman el Valle de El Guarco, ya que estas constituyen condiciones muy favorables para transportarse en bicicleta. Posteriormente se reconocieron las vías y los potenciales puntos de origen y destino de los viajes en la zona.

Para la caracterización de los volúmenes de ciclistas se realizaron conteos automáticos, los cuales consisten en el uso de equipo contador de 
bicicletas, que está compuesto por un dispositivo que cuenta con dos tubos neumáticos (mangueras) que se colocan perpendiculares al flujo de tráfico. El equipo puede detectar bicicletas e ignorar el paso de vehículos motorizados.

Los conteos manuales consistieron en registrar la cantidad de bicicletas que realizan los distintos movimientos posibles en una intersección. Se contaron la cantidad de bicicletas que atraviesan varias intersecciones, con el fin de observar las tendencias de movilidad ciclista, conociendo así, los movimientos que más se realizan y los volúmenes en distintos períodos del día.

La composición urbana al este de la zona de estudio, con múltiples vías y cuadrantes, hace que los conteos de bicicletas en esa zona se encuentren fuera del alcance de este estudio. Por esta razón, se procedió a realizar encuestas origen-destino en tres puntos estratégicos que comunican el sector oeste estudiado con el sector este, de manera que se pueda caracterizar la movilidad hacia la región este. En esta encuesta sólo se le preguntó al ciclista el origen y el destino de su viaje, por lo que se le llamó "encuesta simplificada".

Se efectuó una encuesta pormenorizada en el punto en que se reportó mayor cantidad de ciclistas en los conteos; esta encuesta permitió caracterizar al usuario ciclista, tomando además de orígenes y destinos de los viajes, algunas características del usuario como género y edad, motivos de viaje, características de conducción, motivos de utilización de la bicicleta, entre otras opiniones personales relacionadas con la movilidad. A esta encuesta se le llama "encuesta detallada".

\section{Población}

La definición de los sectores poblados del Valle de El Guarco definió el marco de la zona de estudio, ya que se espera la mayor presencia de ciclistas en las zonas más planas. También la subdivisión de los sectores involucrados permitió la identificación de los distintos puntos a ser origen y destino de los ciclistas, que definen el área muestral de la investigación.

La caracterización de la movilidad ciclista mediante conteos representa a los actuales ciclistas, no así a los potenciales ciclistas (usuarios adicionales que podrían verse atraídos a utilizar la bicicleta en caso de que la infraestructura en el sector sea cicloamigable). Los conteos automáticos se realizaron colocando el equipo en la vía durante un lapso de al menos una semana. Los conteos manuales se efectuaron en un día aleatorio, entre 
martes y jueves, en los períodos pico de dos horas, reportados por los conteos automáticos, los cuales fueron entre 5:00 y 7:00 en la mañana y entre $3: 30$ y $5: 30$ en la tarde.

Dado que muchos ciclistas se dirigían a sus centros de trabajo durante la mañana contaban con una limitada disponibilidad de tiempo, la encuesta origen-destino simplificada se efectuó deteniendo al ciclista para preguntarle únicamente su lugar de origen y de destino de manera que fuese más práctico obtener resultados por parte de los usuarios. La encuesta detallada se desarrolló en el punto de mayor cantidad de ciclistas por día, reportado por los conteos. No se hicieron encuestas a la población potencial a usar la bicicleta como medio de transporte.

\section{Entorno}

El estudio de la movilidad ciclista se llevó a cabo a lo largo de las rutas cantonales y nacionales que se ubican de los distritos San Francisco, Guadalupe y Quebradilla, pertenecientes al cantón Cartago, y en los distritos Tobosi y Tejar del cantón El Guarco, centrándose en las zonas que se encuentran en el Valle de El Guarco. En la figura 2 se muestran los distritos involucrados, así como las vías en la zona, tanto las rutas cantonales como las rutas nacionales. 
Mauricio Torres-Paniagua, Henry Hernández-Vega. Bicycle mobility study in a sector of the Cartago and el Guarco towns of the province of Cartago, Costa Rica

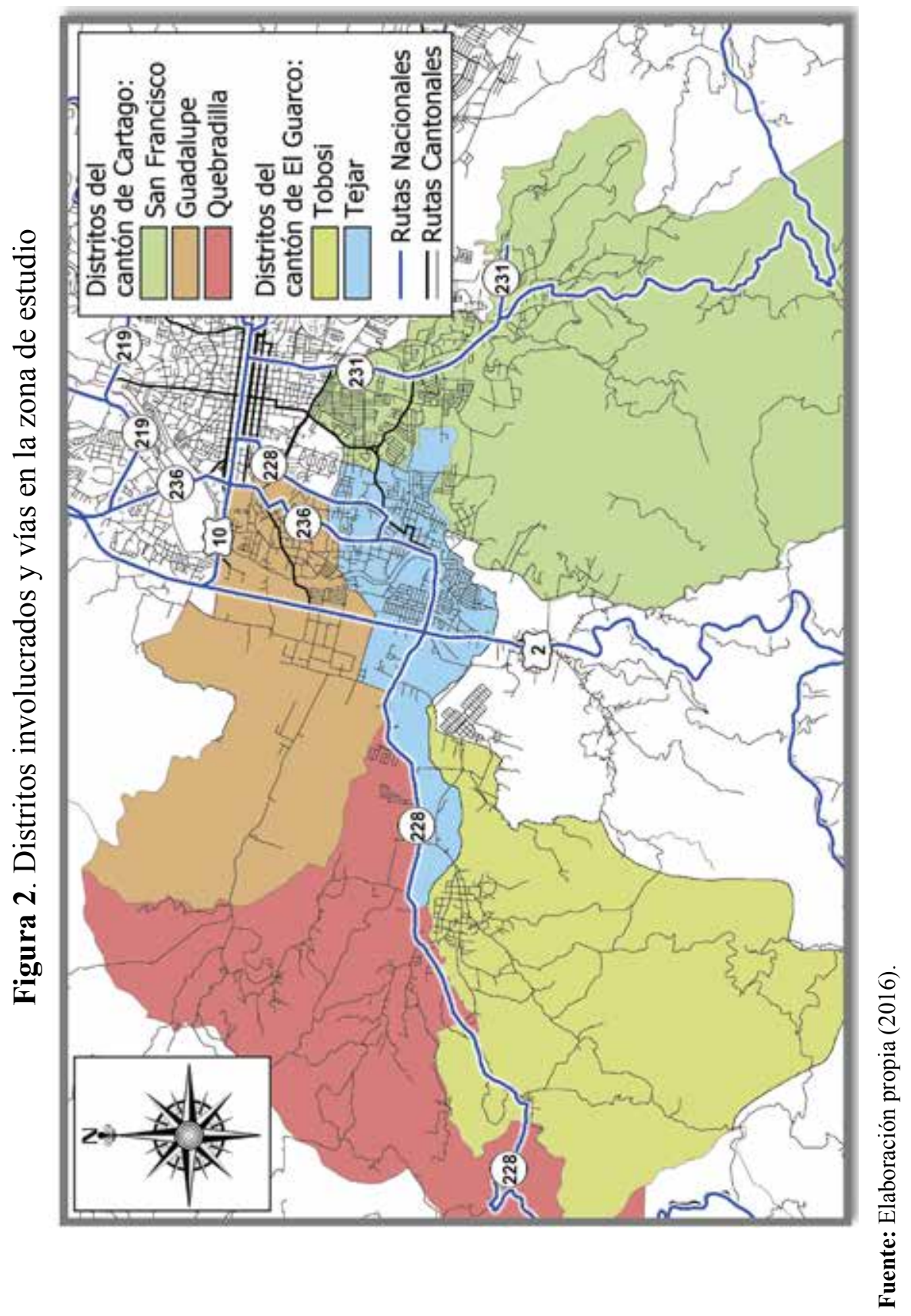


Para la selección de las estaciones de conteo automático y manual, se tomaron ubicaciones consideradas importantes, como en rutas nacionales o calles en puntos estratégicos cercanos al centro de la zona de estudio ya que se determinó que es ahí donde se ubican los generadores de viajes más importantes.

\section{Aforos ciclistas}

Los conteos ciclistas son importantes para planear y operar una red de infraestructura ciclista; dado que permiten identificar donde el uso actual, y su potencial aumento, son altos. Además, son de utilidad para analizar patrones de viajes específicos, entre otros (AASHTO, 2012).

En la figura 3 se muestra el equipo de tubos neumáticos utilizado en el conteo automático de bicicletas. Como se observa en la imagen, se instala la caja del contador junto a algún objeto fijo en la vía (en este caso un poste de concreto), y se colocan dos mangueras separadas a $30 \mathrm{~cm}$ de lado a lado de la calle. El contador posee un sistema interno que almacena los datos de volumen ciclista durante las 24 horas del día. La ubicación de los contadores automáticos tiene que ajustarse a que en el sitio se garantizará una fluidez del tránsito la mayor cantidad del tiempo y otros criterios técnicos para requeridos para su adecuada colocación.

Figura 3. Contador automático de tubos neumáticos

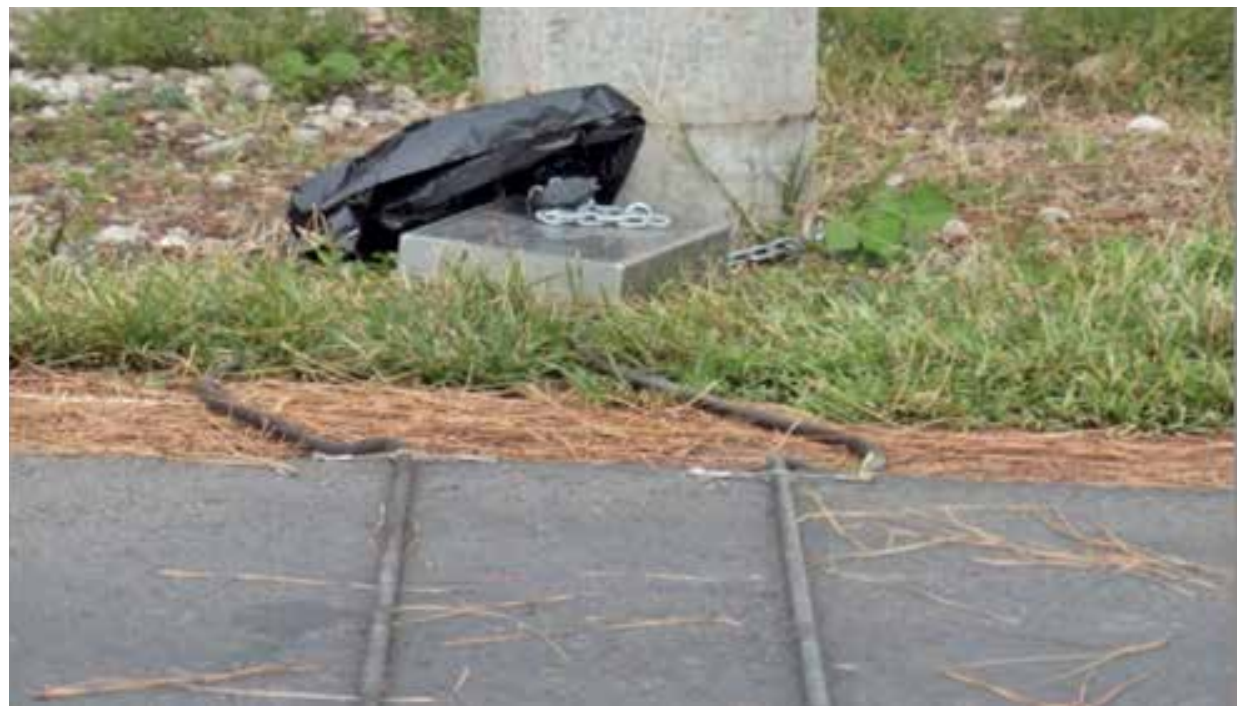

Fuente: Fotografía propia (2016). 
A partir de la información recolectada en los conteos automáticos, la mayoría de los puntos de conteo fueron recopilados en al menos una semana, se caracterizó para cada punto la variación del flujo a distintas horas del día y en los diferentes días de la semana. Se obtuvo el promedio de cantidad diaria de bicicletas en cada punto para el día típico laboral y también se calculó el volumen de estas en los períodos pico de dos horas para la mañana y para la tarde. Con la información del comportamiento del flujo ciclista en las intersecciones, se confeccionaron imágenes que representan los volúmenes de cada movimiento, tanto para el período pico de dos horas de la mañana como para la tarde.

De igual forma se asignaron los volúmenes diarios en cada punto y en cada período pico de dos horas; con estos valores se determinó el porcentaje de bicicletas presentes en dichos períodos respecto al total diario. Con este porcentaje y con los volúmenes en períodos pico de dos horas de las intersecciones de conteo manual, se estimó el total diario en cada corredor de la intersección. De esta manera se asignaron los flujos diarios de ciclistas y se desarrollaron los mapas de movilidad ciclista en la red a partir de la información disponible.

Se construyeron tres mapas de flujos ciclistas, los de volúmenes diarios, de volúmenes en período pico de la mañana y los de período pico de la tarde; dichos mapas permiten observar las tendencias de movilidad en la zona de estudio.

\section{Encuestas}

Los resultados de las encuestas permiten tener un mejor entendimiento de las necesidades y características de los usuarios en bicicleta (Moritz, 1997). Los tres puntos seleccionados para la encuesta origendestino simplificada se definieron en los puentes sobre el río Reventado dentro de la zona de estudio, ya que estos constituyen el único paso de este a oeste en la zona, de manera que se estudien todos los ciclistas que viajan al este de la zona donde se realizaron los conteos.

En la figura 4 se observa que solamente hay tres puntos sobre el río Reventado (puntos 1, 2 y 3 ) que comunican la zona de la parte industrial y rural al oeste, con la parte urbana al este. Estos puntos fueron seleccionados para realizar las encuestas simplificadas. El Punto 4 fue escogido para la encuesta de caracterización al usuario. 
Figura 4. Puntos de encuesta y ubicación del río Reventado en la zona de estudio

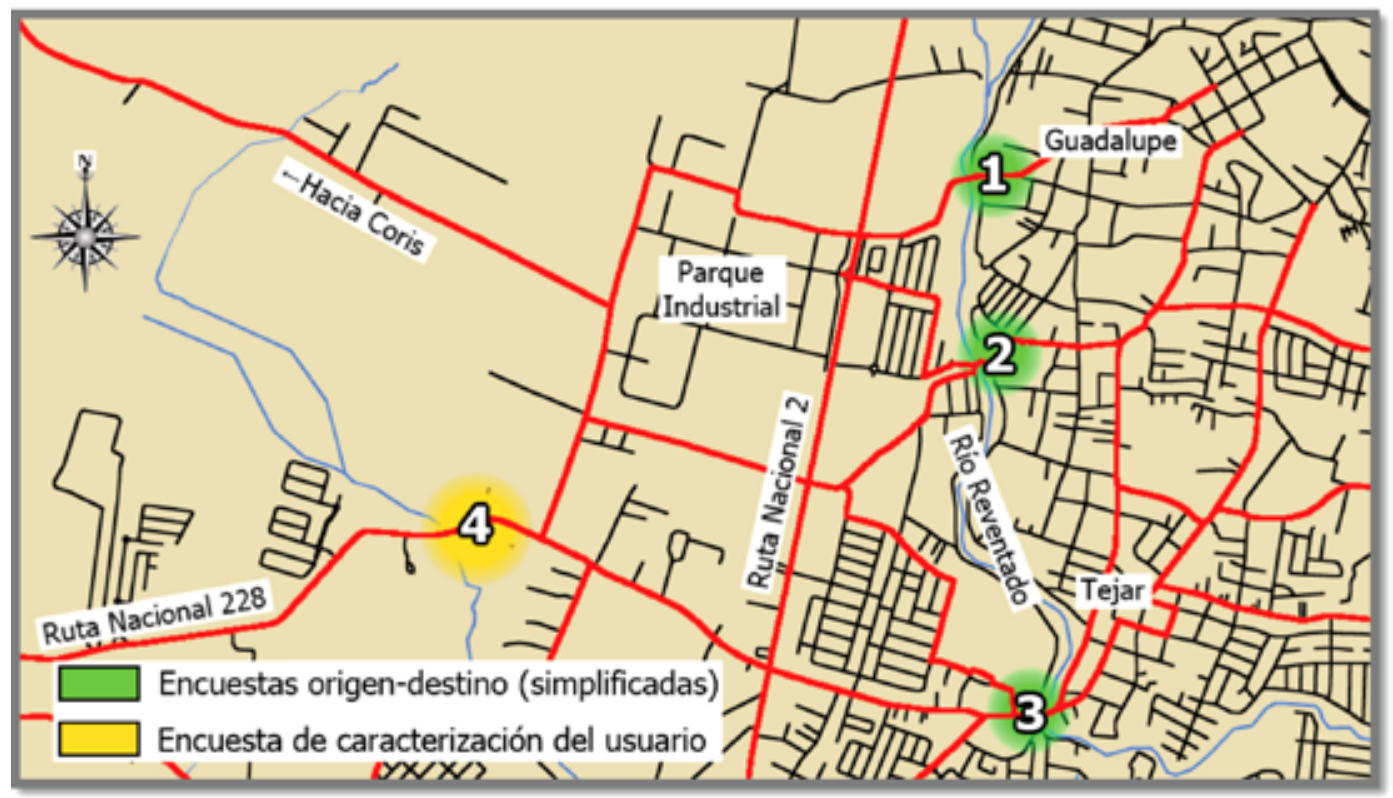

Fuente: Elaboración propia (2016).

\section{Resultados}

El principal resultado generado en esta investigación fue la red de movilidad ciclista trazada a lo largo de toda la zona de estudio. El trazado de la red se fundamentó en la identificación de zonas que generan viajes en bicicleta, su ubicación en una región considerablemente plana, y la caracterización de la actual movilidad ciclista mediante los volúmenes de bicicletas estimados. El resultado de la red de movilidad desarrollada en este estudio se muestra en la figura 5.

En el mapa de la figura 5 se muestra en color amarillo las vías de la red de rutas ciclistas que corresponden a rutas cantonales; en anaranjado se representan las vías que se encuentran en las rutas nacionales, incluyendo la Ruta Nacional 2, la Ruta Nacional 228 y la Ruta Nacional 236. Se observa en la imagen que la configuración de la red comunica coherentemente las distintas zonas generadoras de viajes, teniendo cercano a su centro el sector industrial que es el principal destino de viajes en la zona. 
Figura 5. Red de movilidad ciclista en la zona de estudio

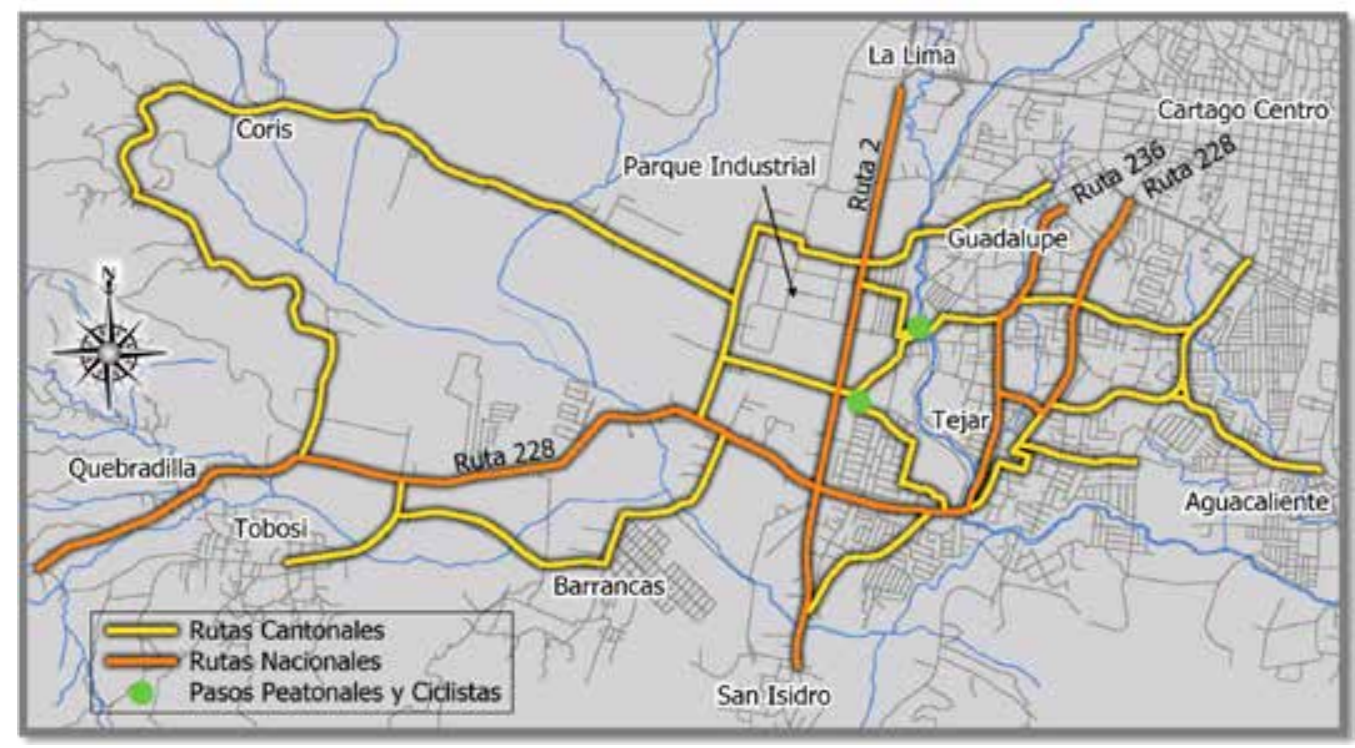

Fuente: Elaboración propia (2016).

La figura 6 muestra la distribución de cantidad de viajes en la semana para uno de los puntos de conteo automático. En el gráfico se evidencia la similitud del comportamiento diario de los viajes en bicicleta en los días laborales (Lunes a Viernes), variando en los fines de semana por la presencia de muchos ciclistas recreativos, principalmente el día domingo. Este comportamiento fue similar en todos los puntos de conteo automático. El primer pico se da cercano a las 6:00 de la mañana y corresponde a viajes hacia los centros de trabajo ubicados principalmente en el sector industrial, y el pico de la tarde corresponde al regreso hacia las zonas de residencia. 
Mauricio Torres-Paniagua, Henry Hernández-Vega. Estudio de la movilidad ciclista en un sector de los cantones Cartago y el Guarco, de la provincia Cartago, Costa Rica

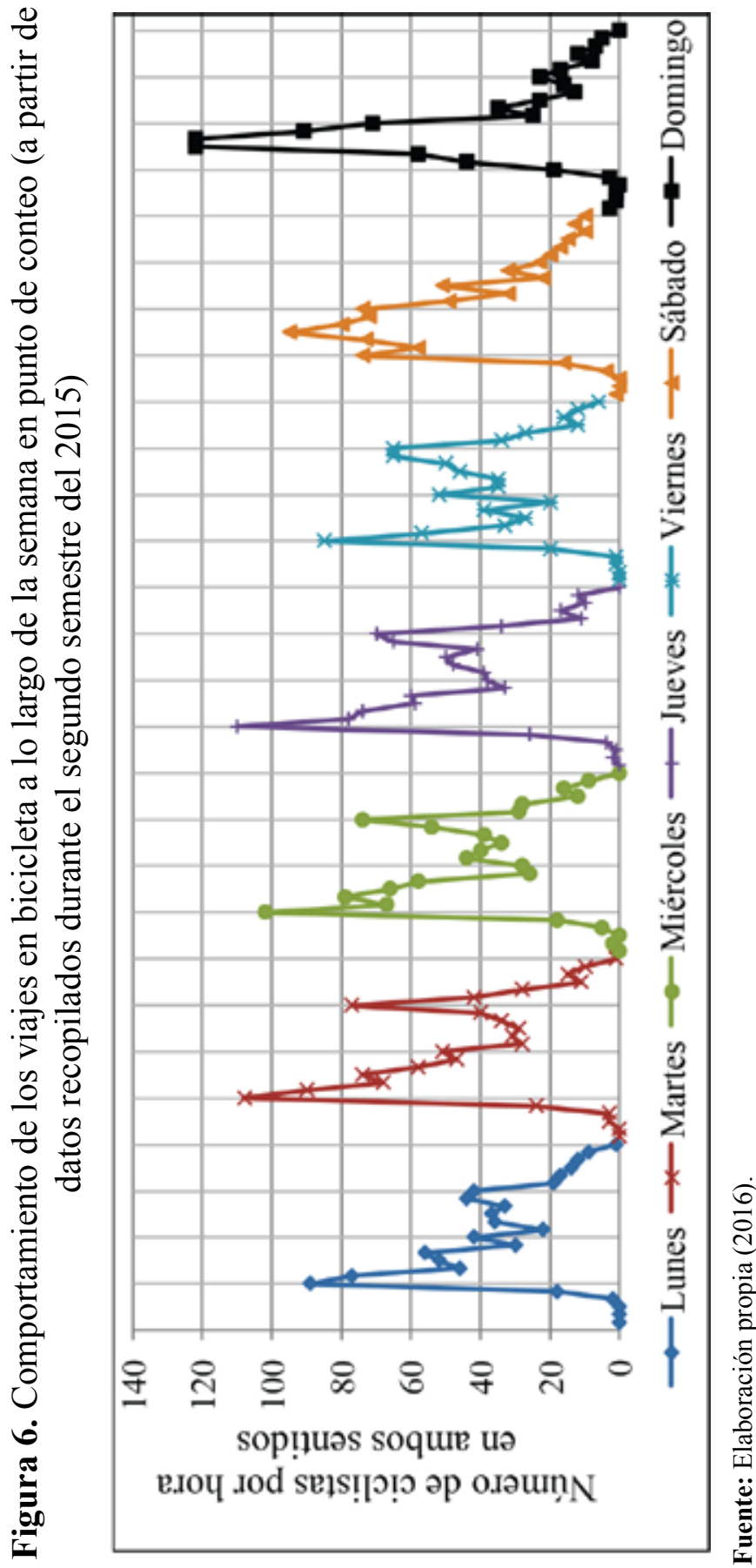


La figura 7 provee un ejemplo de los resultados obtenidos en los conteos manuales en intersecciones, se tienen datos para el período pico de la mañana y de la tarde. Los conteos manuales permiten tener una información más detallada de los patrones de movilidad en las intersecciones.

Figura 7. Resultados de conteos manuales en intersección frente a entrada al Parque Industrial (a partir de datos recopilados durante el segundo semestre del 2015)

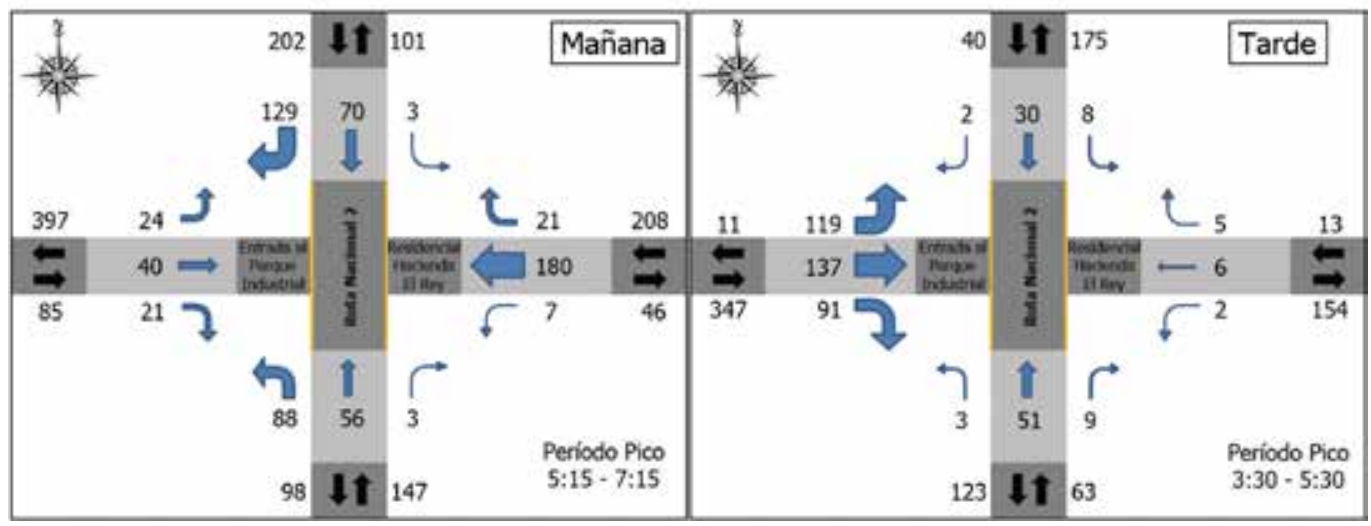

Fuente: Elaboración propia (2016).

La figura 8 indica las tendencias que existen en la movilidad ciclista en la mañana y en la tarde para días entre semana. En la mañana los viajes se dan hacia los centros de trabajo ubicados en el Parque Industrial y alrededores, y en la tarde en dirección contraria hacia los poblados como Tobosi, Tejar o Guadalupe. 
Mauricio Torres-Paniagua, Henry Hernández-Vega. Estudio de la movilidad ciclista en un sector de los cantones Cartago y el Guarco, de la provincia Cartago, Costa Rica

Figura 8. Tendencias de movilidad para días promedio entre semana de los viajes en bicicleta en la zona de estudio

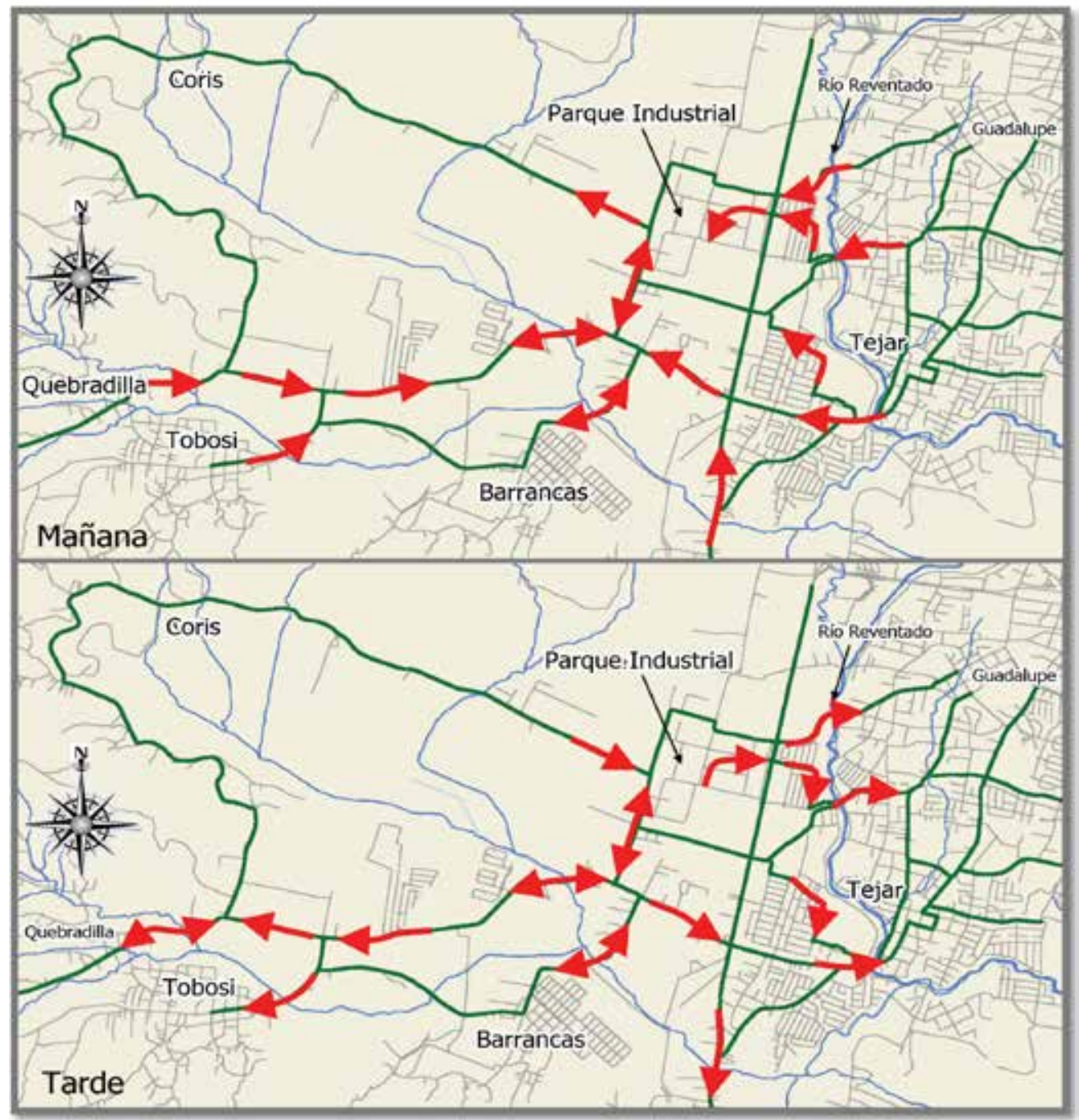

Fuente: Elaboración propia (2016).

Los resultados de la estimación de volúmenes diarios de bicicletas, a partir de conteos automáticos y manuales se encuentran representados en la figura 9. De acuerdo con esta, la Ruta Nacional 228 presenta una cantidad cercana a los 2000 ciclistas diarios; además en algunas vías cercanas al 
Mauricio Torres-Paniagua, Henry Hernández-Vega. Bicycle mobility study in a sector of the Cartago and el Guarco towns of the province of Cartago, Costa Rica

Parque Industrial se reportaron entre 900 y 1200 ciclistas. En los corredores que se dirigen hacia el sector este se estimó una cantidad considerable de ciclistas; se realizan entre 1250 viajes en el puente norte, y alrededor de 1650 en cada uno de los puentes al sur.

Figura 9. Volúmenes diarios para días promedio entre semana de bicicletas estimados a partir de conteos

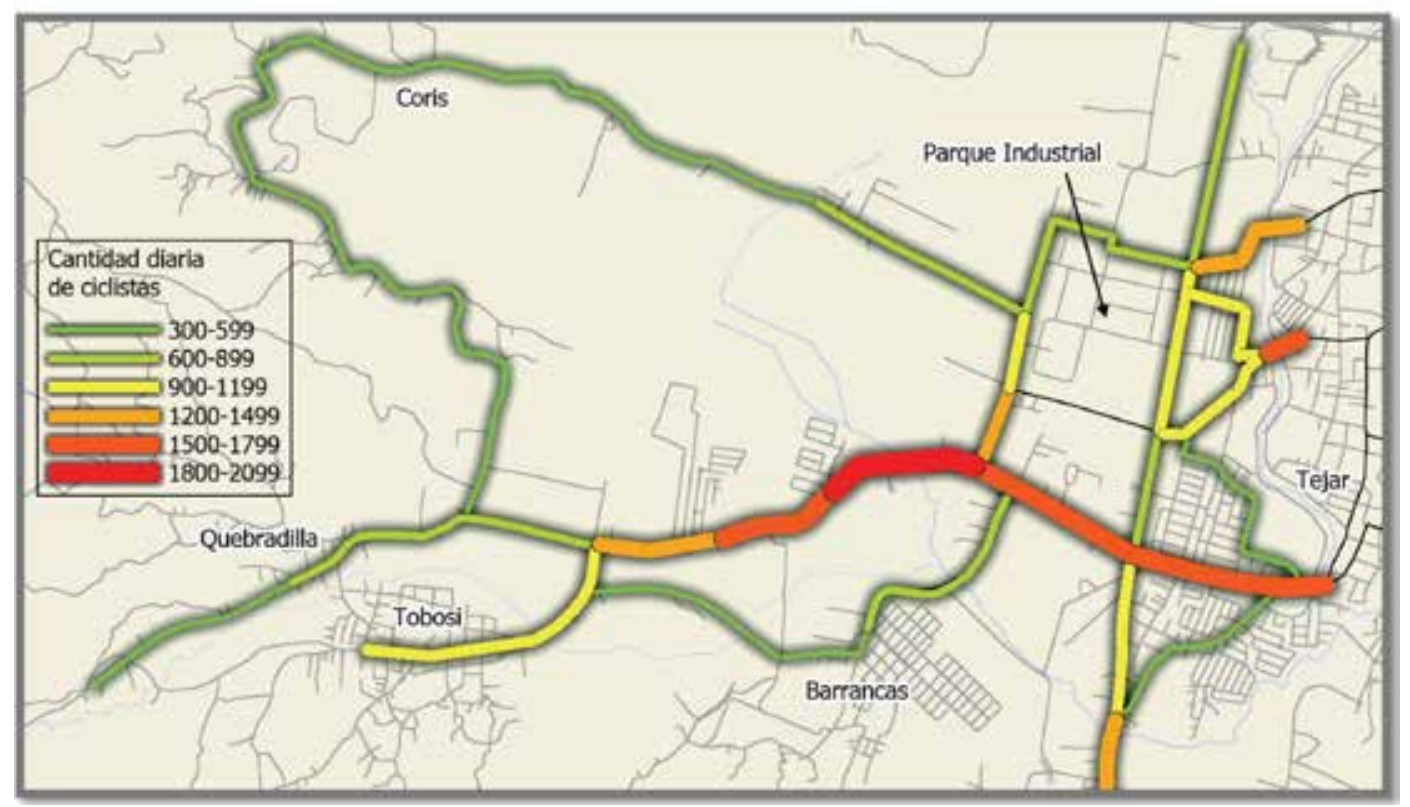

Fuente: Elaboración propia (2016).

A partir de la encuesta origen-destino en los puentes sobre el río Reventado, se desarrolló la imagen que se presenta a continuación en la figura 10, la cual muestra una síntesis de los sectores más frecuentados como destinos, para la caracterización de los viajes hacia el este. 
Mauricio Torres-Paniagua, Henry Hernández-Vega. Estudio de la movilidad ciclista en un sector de los cantones Cartago y el Guarco, de la provincia Cartago, Costa Rica

Figura 10. Principales orígenes y destinos al este de la zona con conteos de ciclistas.

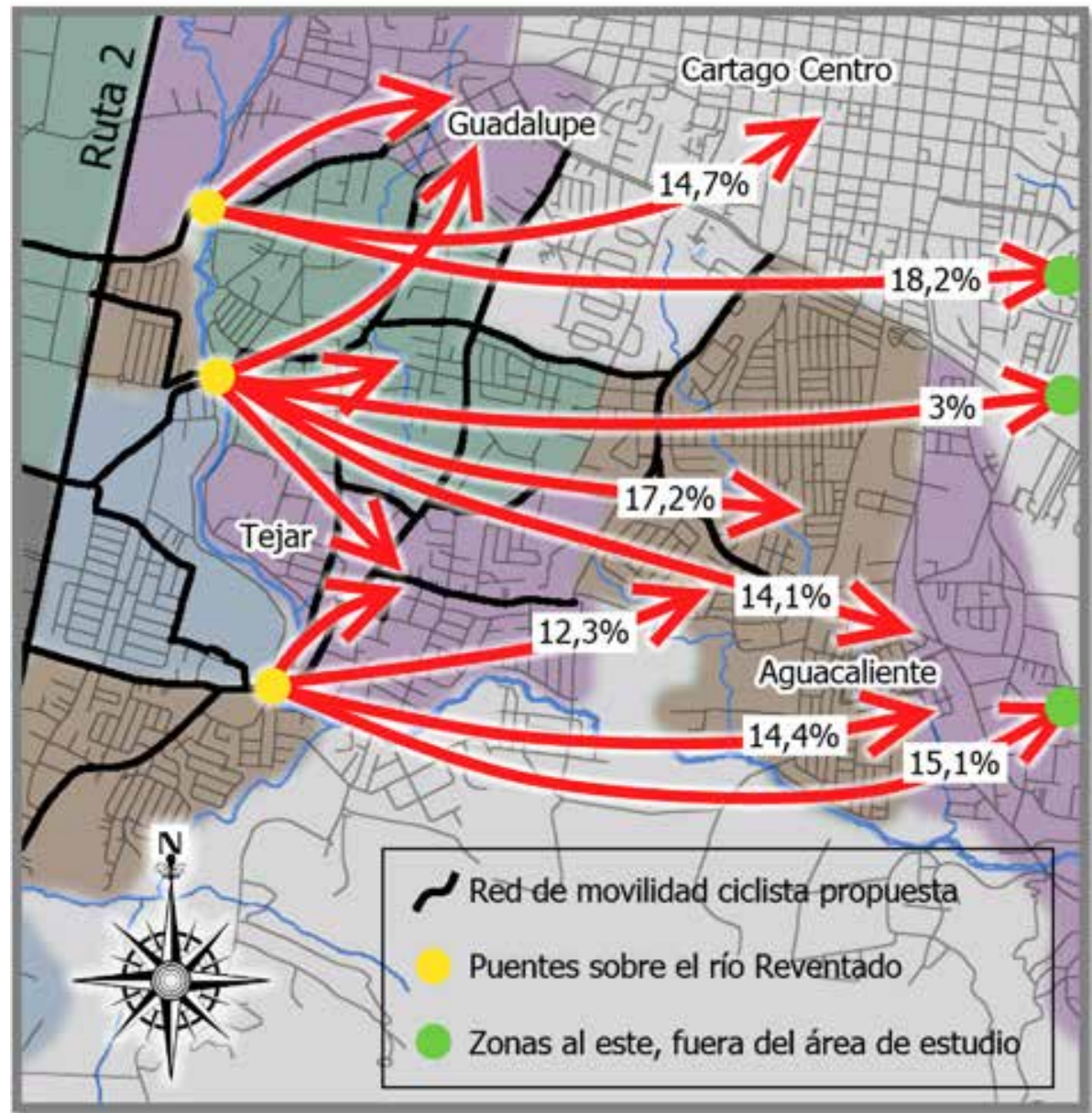

Fuente: Elaboración propia (2016).

Los resultados de las encuestas mostraron que un alto porcentaje de las zonas de destino hacia el este corresponden al centro de Guadalupe, el centro de Tejar y los barrios cercanos a estos centros urbanos. Los viajes que se dirigen a la zona de Cartago centro, sectores residenciales al norte de San Francisco, Aguacaliente, y las zonas al este del área de estudio, son viajes que recorren toda la red ciclista propuesta en el lado este del río Reventado. Sobre el puente norte se estiman 410 viajes diarios que atraviesan 
la red propuesta, en el puente central se estiman 572 viajes diarios atravesando la red, y sobre el puente sur se estiman 681 viajes en bicicleta.

Dado que los aforos de ciclistas se realizaron al oeste del río Reventado las encuestas simplificadas permitieron tener el desglose de la distribución de los viajes en tres puntos ubicados en puentes sobre este río. En la encuesta simplificada únicamente se hicieron las preguntas ¿de dónde viene? y ¿hacia dónde va? Esto permitió obtener una distribución de los viajes por orígenes o destinos en los diferentes puntos y proyectar los viajes aforados al este de la zona de estudio tal como se muestra en las figuras 11, 12 y 13. La encuesta detallada también permitió contar con información sobre los orígenes y destinos en el sector de la calle La Rueda (ver Figura 14).

El tamaño de la muestra se calculó con la ecuación propuesta por Ortúzar (2000):

$$
n \geq \frac{p(1-p)}{\left(\frac{e}{z}\right)^{2}+\frac{p(1-p)}{N}}
$$

donde:

n: tamaño de muestra a encuestar.

p: proporción de viajes con un destino determinado.

e: nivel aceptable de error.

z: variable normal estándar para el nivel de confianza requerido.

$\mathbf{N}$ : población total (volumen de ciclistas).

En total se realizaron 446 encuestas simplificadas donde la información brindada por los ciclistas se centró en sus orígenes y destinos y 74 encuestas detalladas. 
Mauricio Torres-Paniagua, Henry Hernández-Vega. Estudio de la movilidad ciclista en un sector de los cantones Cartago y el Guarco, de la provincia Cartago, Costa Rica

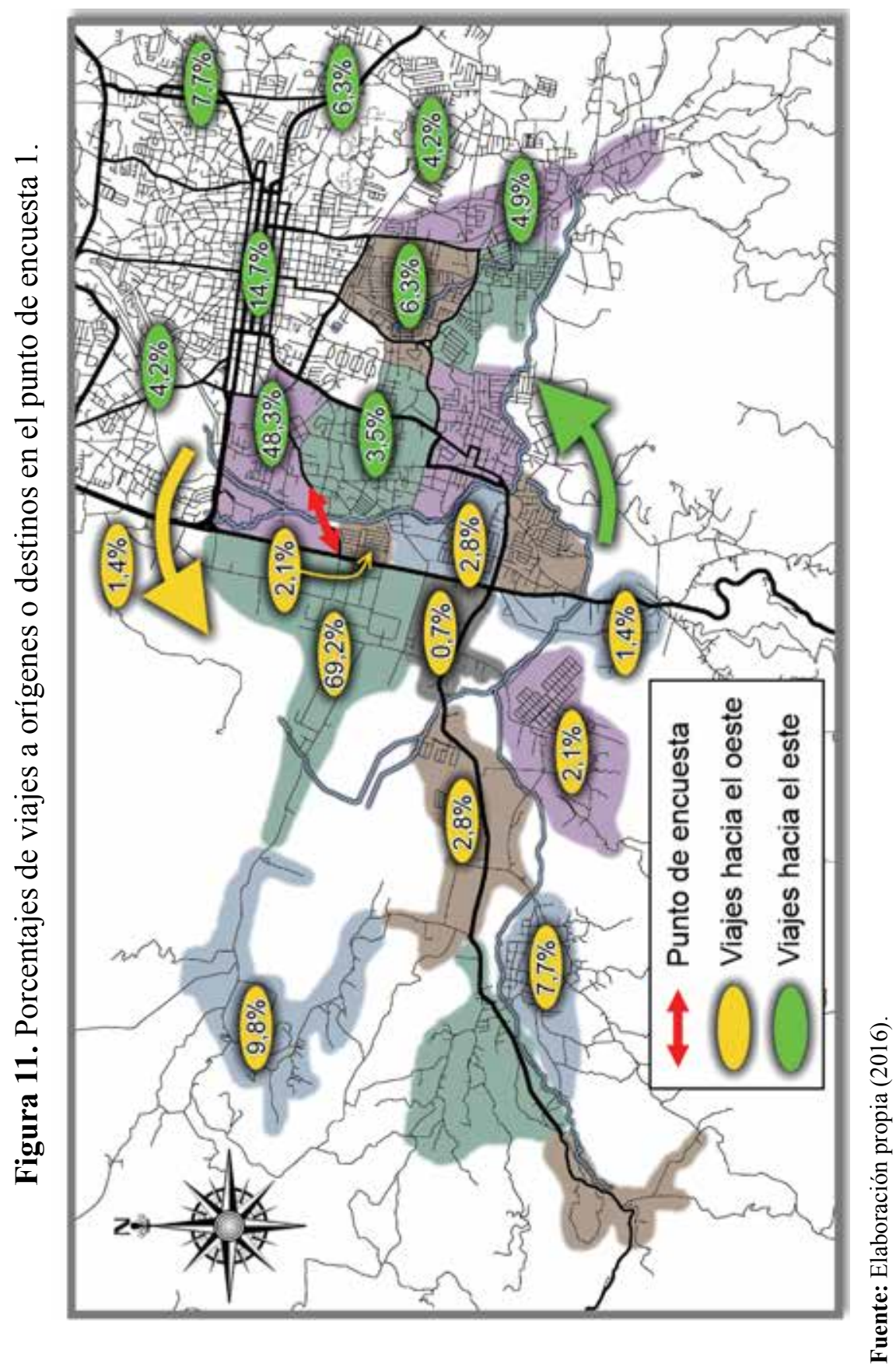


Mauricio Torres-Paniagua, Henry Hernández-Vega. Bicycle mobility study in a sector of the Cartago and el Guarco towns of the province of Cartago, Costa Rica

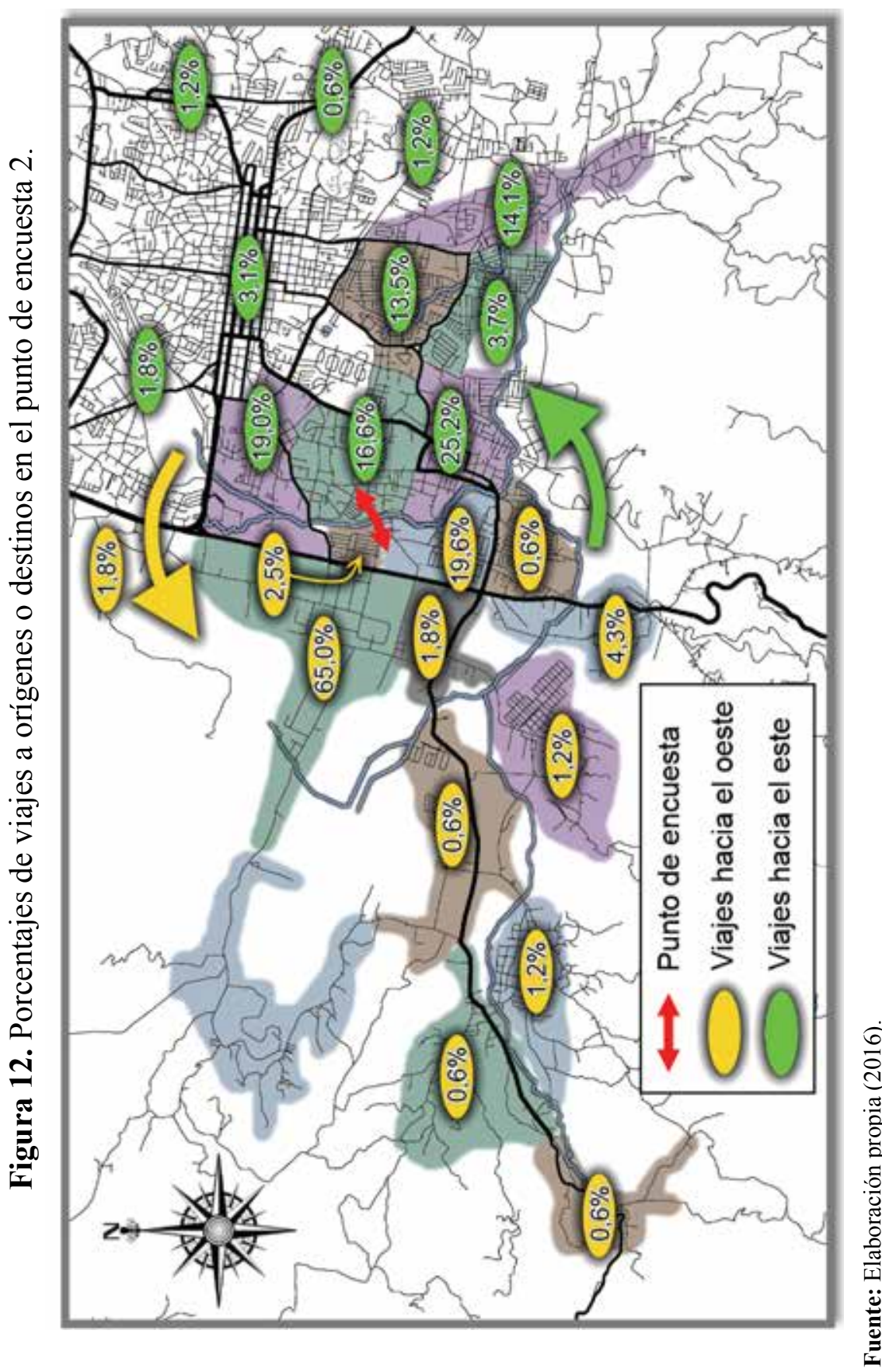


Mauricio Torres-Paniagua, Henry Hernández-Vega. Estudio de la movilidad ciclista en un sector de los cantones Cartago y el Guarco, de la provincia Cartago, Costa Rica

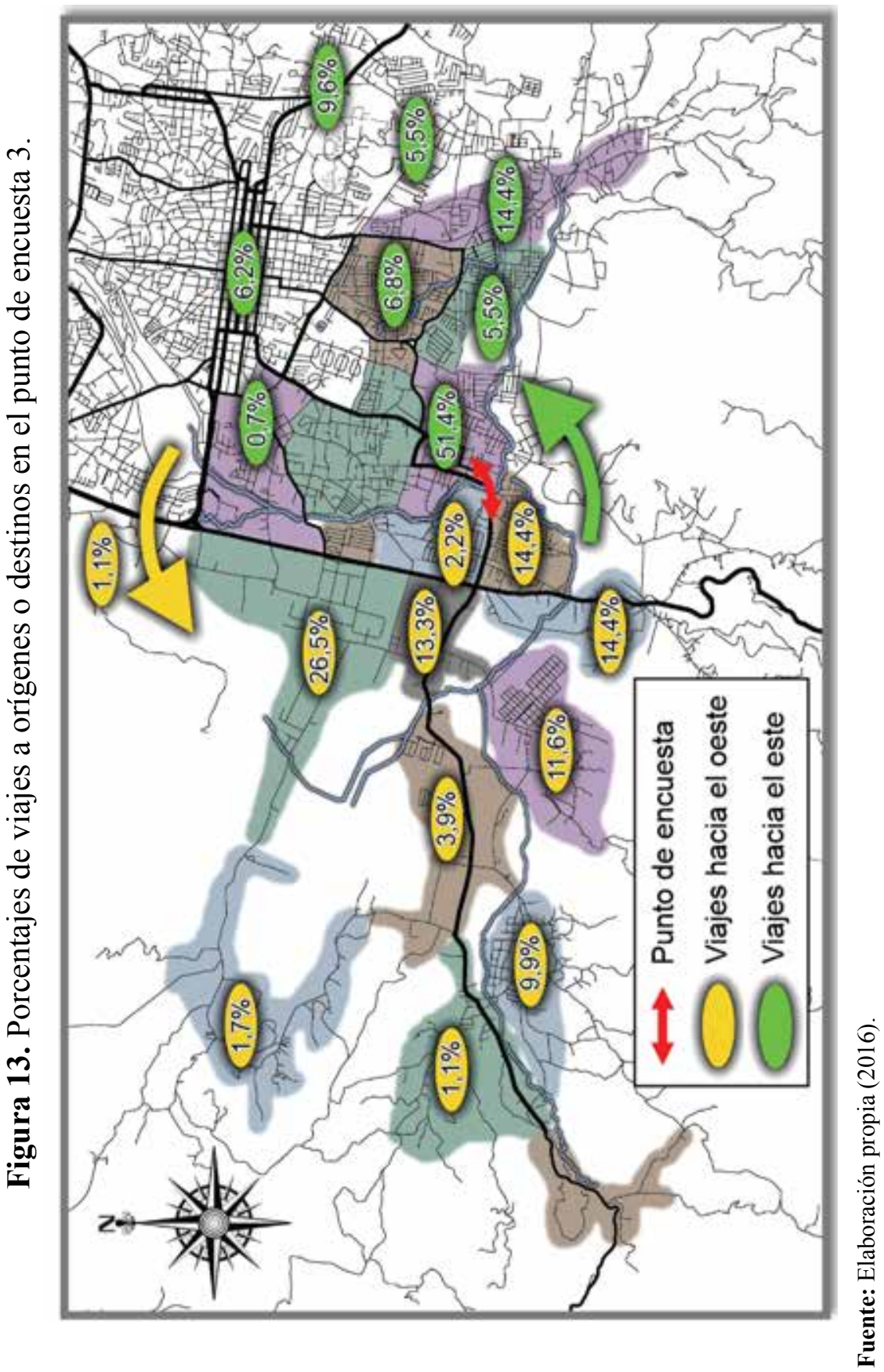


Mauricio Torres-Paniagua, Henry Hernández-Vega. Bicycle mobility study in a sector of the Cartago and el Guarco towns of the province of Cartago, Costa Rica

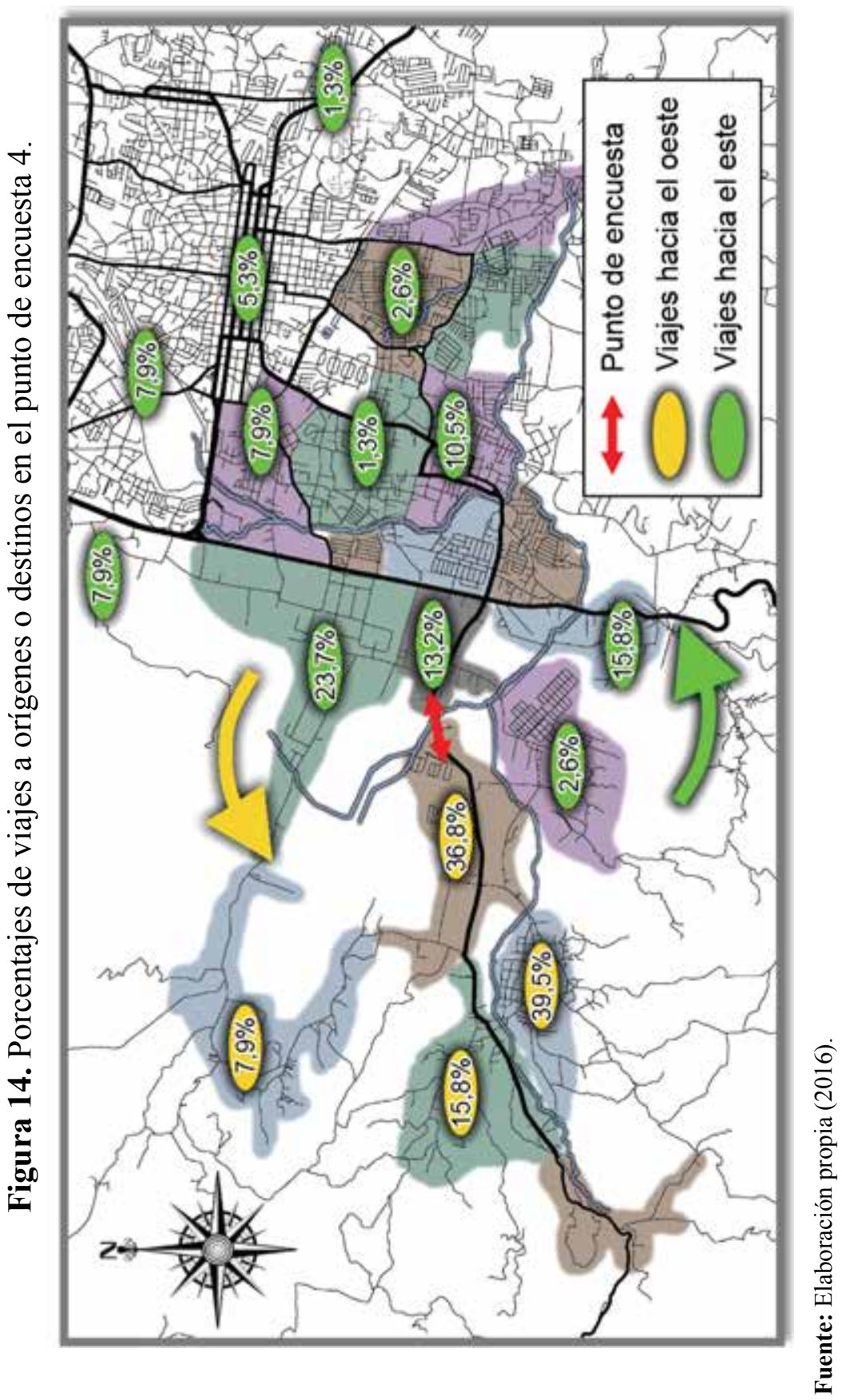


La encuesta detallada se realizó en el sector conocido como Calle La Rueda en la Ruta Nacional Número 228. El $71 \%$ de las respuestas obtenidas corresponden a ciclistas, los cuales se encuentran entre los $20 \mathrm{y}$ 40 años de edad (ver Tabla 1), en su gran mayoría del género masculino.

Tabla 1. Edades de los usuarios de bicicleta en la zona $(n=74)$

\begin{tabular}{|c|c|}
\hline Rango de Edad (años) & \% \\
\hline 20 o menos & 4 \\
\hline $21-30$ & 49 \\
\hline $31-40$ & 22 \\
\hline $41-50$ & 17 \\
\hline $51-60$ & 5 \\
\hline Más de 60 & 3 \\
\hline
\end{tabular}

Fuente: Elaboración propia (2016).

De acuerdo con la Tabla 2, un $67 \%$ de los encuestados únicamente cuentan con educación primaria. El 27,6 \% indicaron que sus núcleos familiares tienen un ingreso económico mensual inferior o igual a los 200 mil colones, un $65,8 \%$ proviene de núcleos familiares con un ingreso económico entre los 200 a los 400 mil colones, y solamente un 6,7\% de los encuestados cuenta con ingresos superiores a los 400 mil colones. Únicamente el $15 \%$ de los ciclistas encuestados dijo poseer licencia de conducir.

Tabla 2. Escolaridad de los usuarios de bicicleta en la zona $(n=74)$

\begin{tabular}{|c|c|}
\hline Escolaridad & $\mathbf{\%}$ \\
\hline Primaria Incompleta & 9 \\
\hline Primaria Completa & 58 \\
\hline Secundaria Completa & 30 \\
\hline Técnico & 3 \\
\hline Universitaria & 0 \\
\hline
\end{tabular}

Fuente: Elaboración propia (2016).

El 98,7\% de los encuestados son de género masculino. Por otro lado, en algunas zonas como los centros de distrito se puede observar una mayor presencia de usuarios del género femenino, pero siempre en proporciones muy pequeñas. 
Un $96 \%$ de los ciclistas revelaron que el trabajo era su propósito de viaje en bicicleta y el $93 \%$ de los encuestados laboran al menos una jornada laboral completa. El 97 \% utilizan la bicicleta al menos cinco días en la semana y el $70 \%$ la utiliza bicicleta desde hace más de 10 años. Los ciclistas en la zona, en términos generales, no utilizan equipo de seguridad como casco y chaleco en sus viajes.

\section{Discusión}

Los datos recopilados en las encuestas indican que actualmente esta alternativa de transporte es utilizada solamente por un sector de la población, por ejemplo la cantidad de mujeres en bicicleta era reducido. Este modo de transporte debe estar al alcance de todos, sin importar género y edad. Además, se evidencia que en una gran mayoría la bicicleta se utiliza principalmente para ir a trabajar.

Es alarmante que en algunos puntos de la Ruta Nacional 2 se den actualmente hasta 1300 viajes diarios en bicicleta, considerando que esta ruta nacional primaria no posee ningún tipo de infraestructura para el ciclista, las altas velocidades que se pueden presentar en la ruta y el paso frecuente de vehículos pesados.

En las horas de la mañana se evidenció una tendencia en la movilidad ciclista en dirección hacia los centros de trabajo concentrados en la zona industrial, ubicados principalmente en el distrito de Guadalupe de Cartago, al oeste de la Ruta Nacional 2. En la tarde la tendencia de movilidad se da en dirección hacia las poblados o zonas residenciales en la periferia de dicha zona industrial.

Cerca de 2000 ciclistas transitando por día se reportaron en la Ruta Nacional 228 en las cercanías de barrio Sabana Grande hacia el oeste; constituye la vía con más cantidad de viajes en bicicleta en la red de movilidad.

Existen numerosas formas de diseñar la infraestructura y facilidades para ciclistas; en Costa Rica se debe promover cada vez más el desarrollo de conocimiento relacionado con el transporte en bicicleta para fomentarlo.

La red de movilidad propuesta, es el conjunto de rutas que actualmente utilizan los ciclistas. A través de estas rutas se unen coherentemente los puntos más frecuentados para ser origen o destino en la zona. En la figura 15 se presenta la recomendación de infraestructura ciclista a adoptar en las distintas vías de la zona. 
Figura 15. Tipos de infraestructura propuesta para las vías en la zona de estudio

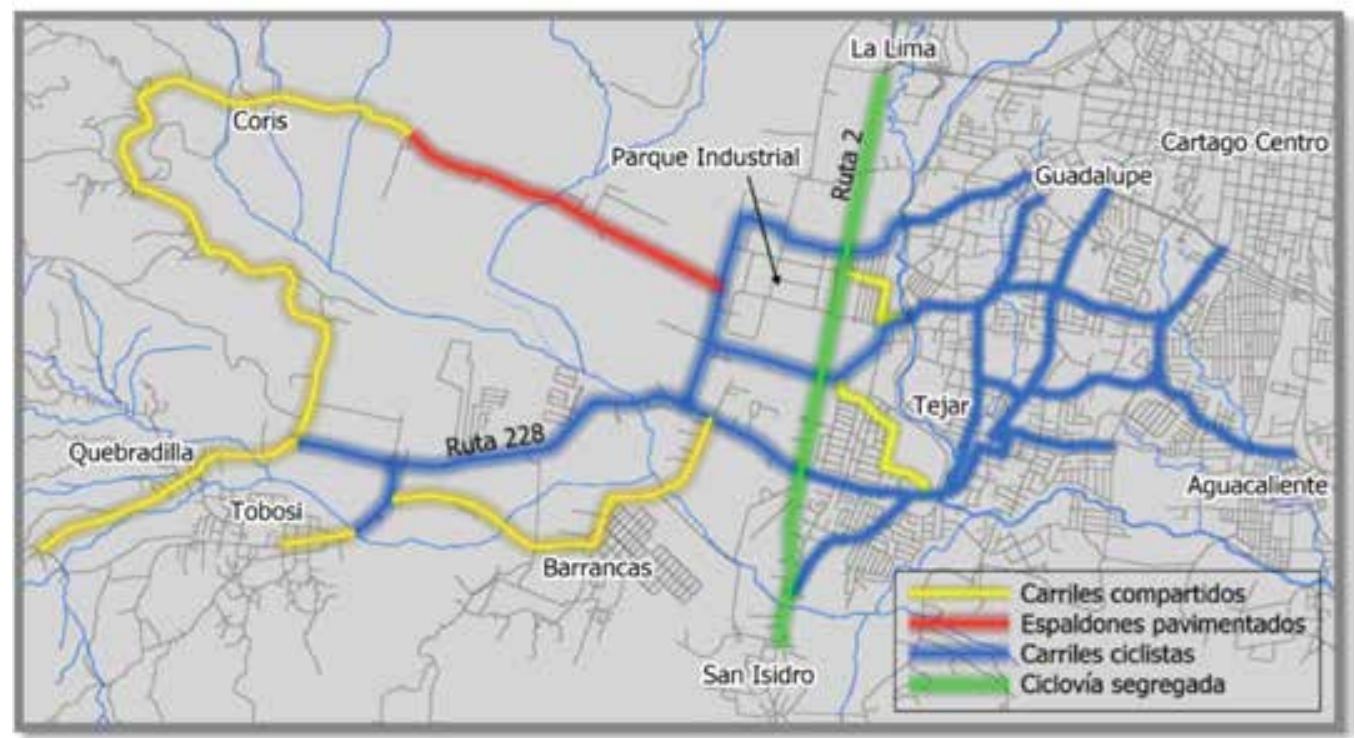

Fuente: Elaboración propia (2016).

La infraestructura ciclista recomendada concuerda con los criterios de la Guía de Diseño y Evaluación de Ciclovías para Costa Rica (AcuñaLeiva, Hernández-Vega, Jiménez-Romero, Zamora-Rojas y Loría-Salazar, 2016). Por ejemplo, la ciclovía segregada se recomienda debido a las características funcionales de la Ruta Nacional 2, como la alta velocidad de los vehículos y alto porcentaje de vehículos pesados, en la zona de estudio.

El hecho de observar la gran cantidad de ciclistas que transitan actualmente en la zona y la falta de facilidades para ciclistas, a pesar de la disponibilidad de espacio en los márgenes de las calles, es preocupante. Los resultados del presente estudio podrían motivar a la administración para promover la movilidad no motorizada de la zona, considerando que es una región plana propicia para la movilidad en bicicleta.

Es recomendable la construcción de aceras paralelas a la construcción de la infraestructura ciclista recomendada con el fin de proveer una adecuada red de movilidad peatonal, dado que la infraestructura para peatones es deficiente en la zona. 
De acuerdo con Pucher, Dill \& Handy (2010), para lograr un incremento en la cantidad de viajes en bicicleta se requiere un paquete integral de intervenciones que no solamente se enfocan a la intervención de la infraestructura, por lo que las recomendaciones del presente estudio deben de complementarse con medidas que van desde la construcción de parqueos para bicicletas hasta campañas de educación para ciclistas y conductores.

Solamente en los puentes sobre el río Reventado se registraron 1600 viajes diarios cuyo origen o destino se encuentra al este, atravesando toda la red de movilidad propuesta; este número no incluye a los ciclistas que se mueven internamente en el sector este.

Los ciclistas encuestados corresponden a usuarios jóvenes y mayoritariamente hombres, cuyo propósito de viaje es el trabajo. Este tipo de usuario pertenece a un estrato socioeconómico específico, con escolaridad baja en su mayoría. El usuario utiliza la bicicleta regularmente y en su mayoría es ciclista experimentado con más de 10 años de uso de la bicicleta. Muy pocos usuarios utilizan equipo de seguridad en sus viajes, como casco y chaleco reflectante.

En general las vías pertenecientes a la red de movilidad, presentan características espaciales que permitirían adoptar infraestructura en favor del transporte en bicicleta, como carriles ciclistas, espaldones pavimentados y ciclovías segregadas.

Los perfiles de los usuarios actuales de la bicicleta permitiría identificar zonas potenciales donde existan usuarios con perfiles similares a los identificados y planificar la movilidad a futura tomando en cuenta los futuros desarrollos industriales y residenciales esperados en la zona.

\section{Referencias}

AASHTO (2012). Guide for the Development of Bicycle Facilities. Fourth Edition. American Association of State Highway and Transportation Officials. Estados Unidos.

Acuña-Leiva, R., Hernández-Vega, H., Jiménez-Romero, D., Zamora-Rojas, J. y Loría-Salazar, L. G. (2016). Guía de diseño y evaluación de ciclovías para Costa Rica. Programa Infraestructura del Transporte. Laboratorio Nacional de Materiales y Modelos Estructurales. Universidad de Costa Rica San José, Costa Rica. 
Australian Bicycle Council (2010). The Australian National Cycling Strategy 2011-2016. Austroads. Sydney Australia.

Ayuntamiento de Madrid (2008). Plan Director de Movilidad Ciclista de Madrid. Dirección General de Planificación del Área de Obras y Espacios Públicos del Ayuntamiento de Madrid. Recuperado de: http:// www.madrid.es/portales/munimadrid/es/Inicio/Ayuntamiento/Movilidad-y-Transportes/Oficina-de-la-bici/Plan-Director-de-Movilida d-Ciclista?vgnextfmt $=$ detNavegacion\&vgnextoid $=09$ bccea83e $67 \mathrm{a} 1$ 10VgnVCM2000000c205a0aRCRD\&vgnext

Ayuntamiento de Vitoria-Gasteiz (s.f.). Plan Director de Movilidad Ciclista de Vitoria-Gasteiz 2010-2015. España. Recuperado de: http:// www.vitoria-gasteiz.org/wb021/http/contenidosEstaticos/adjuntos/ es/45/63/34563.pdf

Canadian Institute of Transportation Engineers (2004) Promoting Sustainable Transportation Through Site Design. An ITE Proposed Recommended Practice. Institute of Transportation Engineers. Estados Unidos de América.

City of Calgary (1997). The Calgary Cycle Plan (1996). Transportation Department. Canadá. Recuperado de: http://www.calgary.ca/Transportation/TP/Pages/Cycling/Cycling-Strategy/Calgary-CyclePlan.aspx

CROW (2006). Manual de Diseño para el Tráfico de Bicicletas. Holanda. Recuperado de: http://www.ciclovida.ufpr.br/wp-content/uploads/2011/07/bpp_pdf/Manual\%20Dise \%C3\%B1o\%20 Tr\%C3\%A1fico\%20Bicicletas\%20\%5BCROW\%5D.pdf

Dobles, M. (1981). Circulación en bicicleta en el área metropolitana de San José. Proyecto de investigación. Universidad de Costa Rica. San José, Costa Rica

Fonseca, F. (2010). Evaluación de la factibilidad de la implementación de ciclo vías para la movilización de estudiantes hacia la Ciudad Universitaria Rodrigo Facio. Informe final de trabajo final de graduación. Universidad de Costa Rica

Gobierno de Cantabria (2012). Plan de Movilidad Ciclista de Cantabria. Consejería de Medio Ambiente. España. Recuperado de: http:// www.cantabria.es/web/pmcc/documentacion 
Gobierno Regional Metropolitano de Santiago (sin fecha). El Plan Maestro de Ciclo Rutas del Bicentenario. Chile. Recuperado de: http://www. paho.org/blogs/dds-sociedadcivil/wp-content/uploads/2011/09/CicloRutasBicentenario.pdf

Gobierno Regional Metropolitano de Santiago (2012). Revisión y Actualización del Plan Maestro de Ciclovías y Plan de Obras. Chile.

ITDP (2011). Manual integral de movilidad ciclista para ciudades mexicanas (Tomos I, II, III, IV, Vy VI). Instituto para Políticas de Transporte y Desarrollo. México DF, México. Recuperado de http://www. ciclociudades.org/

Laverty, A. A., Mindell, J. S., Webb, E. A., \& Millett, C. (2013). Active travel to work and cardiovascular risk factors in the United Kingdom. American Journal of Preventive Medicine, 45(3), 282-288.

L.C.R. Logística S.A. (2007). Estudio de oferta y demanda de transportes de la GAM. Informe Final. Tomo I. Modelo de Demanda - Oferta de Transporte Urbano en la Gran Área Metropolitana de Costa Rica. Ministerio de Vivienda y Asentamientos Humanos, PRUGAM. San José, Costa Rica.

Los Angeles Department of City Planning (2011). 2010 Bicycle Plan: A component of the city of Los Angeles transportation element. Estados Unidos. Recuperado de: http://planning.lacity.org/cwd/gnlpln/transelt/NewBikePlan/Txt/LA\%20CITY\%20BICYCLE\%20 PLAN.pdf

Machado, R. (2010). Modelización de la demanda potencial de viajes en bicicleta en la Gran Área Metropolitana. Informe final de trabajo final de graduación. Universidad de Costa Rica.

Ministerio de Transporte de Colombia. (2016). Guía de ciclo-infraestructura para ciudades colombianas. (C. Pardo \& A. Sanz, Eds.). Bogotá D.C.: Ministerio de Transporte de Colombia.

MOPT (2008). Informe DGIT-ED-2215-2008 Solicitud para la instalación de facilidades para ciclistas sobre la Ruta Nacional Primaria $N^{\circ} 2$ en las inmediaciones de la Zona Franca de Cartago y del Restaurante El Quijongo en El Guarco, Cartago. Dirección General de Ingeniería de Tránsito. Ministerio de Obras Públicas y Transportes. Costa Rica. 
Moritz, W. (1997). Survey of North American bicycle commuters: design and aggregate results. Transportation Research Record: Journal of the Transportation Research Board, (1578), 91-101.

Ortúzar, J. (2000). Modelos de Demanda de Transporte. México: ALFAOMEGA S.A.

Otoya. (2009). Estimación económica de las principales deseconomías presentes en el Gran Área Metropolitana (GAM) de Costa Rica. Revibec: Revista Iberoamericana de Economía Ecológica, 13, 15-27.

Pucher, J., Dill, J., \& Handy, S. (2010). Infrastructure, programs, and policies to increase bicycling: an international review. Preventive medicine,50, S106-S125.

Secretaría del Medio Ambiente del Gobierno del Distrito Federal (2012). Estrategia de movilidad en bicicleta de la ciudad de México. Recuperado de: http://martha.org.mx/una-politica-con-causa/wp-content/ uploads/2013/09/10-Estrategia-Movilidad-en-Bicicleta.pdf

Torres, M. (2016) Estudio de la movilidad ciclista en los distritos de San Francisco, Guadalupe y Quebradilla del cantón de Cartago, y los distritos de Tobosi y Tejar del Cantón de El Guarco. Informe final de trabajo final de graduación. Universidad de Costa Rica. 